\title{
Synthesis and Characterization of Chromium Oxide Nanoparticles
}

\author{
VIVEK SHEEL JASWAL, AVNISH KUMAR ARORA*, \\ MAYANK KINGER, VISHNU DEV GUPTA and JOGINDER SINGH \\ Department of Chemistry, Maharishi Markendeshwer University, Mullana - 133207, India. \\ ${ }^{*}$ Corresponding author E-mail: aroradcy@gmail.com \\ http://dx.doi.org/10.13005/ojc/300220
}

(Received: April 15, 2014; Accepted: May 16, 2014)

\begin{abstract}
Chromium oxide nanoparticles (NPs) have been rapidly synthesized by precipitation method using ammomia as precipitating agent and are characterized by using X-ray Diffraction (XRD), Thermo Gravimetric Analysis (TGA), UV-Visible absorption (UV), Infrared Spectoscopy (IR), Scanning Electron Microscopy (SEM) and Transmission Electron Microscopy (TEM). XRD studies show that chromium oxide NP is formed as $\mathrm{Cr}_{2} \mathrm{O}_{3}$ and it has hexagonal structure. The shape and particle size of the synthesized $\mathrm{Cr}_{2} \mathrm{O}_{3} \mathrm{NPs}$ is determined by SEM and TEM. The images showed that the size of NPs of $\mathrm{Cr}_{2} \mathrm{O}_{3}$ varied from $20 \mathrm{~nm}$ to $70 \mathrm{~nm}$ with average crystalline size $45 \mathrm{~nm}$. UVVisible absorption and IR spectoscopy confirm the formation of nanosized $\mathrm{Cr}_{2} \mathrm{O}_{3}$. TGA verifies that the $\mathrm{Cr}_{2} \mathrm{O}_{3}$ NPs are thermally stable upto $1000^{\circ} \mathrm{C}$.
\end{abstract}

Key words: Nanaoparticles, chromium oxide, TEM, metal oxides, XRD analysis.

\section{INTRODUCTION}

Transition metal oxide NPs have many applications as catalyst ${ }^{1-5}$, sensors ${ }^{6-9}$, superconductors ${ }^{10-11}$ and adsorbents ${ }^{12-13}$. Metaloxides constitute an important class of materials that are involved in environmental science, electrochemistry, biology, chemical sensors, magnetism and other fields. Chromium oxides have attracted much attention recently because of their importance both in science and technology. As the chromium have different stable oxidation states, it can form the different types of oxides. Special attention has been focused on the formation and properties of chromium oxide $\left(\mathrm{Cr}_{2} \mathrm{O}_{3}\right)$, which is important in specific applied applications such as in high temperature resistant materials[14], corrosive resistant materials ${ }^{15}$, liquid crystal displays ${ }^{16,17}$, green pigment ${ }^{18}$, catalysts ${ }^{19,20}$ and so on. It is well known that intrinsic properties of inorganic materials are mainly determined by their composition, structure, crystallinity, size and morphology; great efforts have been devoted to the investigation of different $\mathrm{Cr}_{2} \mathrm{O}_{3}$ materials synthesis ${ }^{21-}$ 23. 
Various techniques have been developed to synthesize $\mathrm{Cr}_{2} \mathrm{O}_{3}$ NPs such as precipitation ${ }^{24}$, precipitation gelation ${ }^{25-27}$, sol gel ${ }^{28-30}$, mechanochemical reaction, oxidation of chromium in oxygen ${ }^{31}$ and sonochemical method ${ }^{32}$. Among all these methods as mentioned, chemical reduction in aqueous solvents exhibits the greatest feasibility to be extended to further applications in terms of its simplicity and low cost. In the present work we have reported the synthesis of $\mathrm{Cr}_{2} \mathrm{O}_{3} \mathrm{NPs}$ by aqueous precipitation using ammonia as precipitating agent and $\mathrm{Cr}_{2}\left(\mathrm{SO}_{4}\right)_{3}$ as the source of chromium. Khatoon et al., ${ }^{33}$ reported the internalization of $\mathrm{Cr}_{2} \mathrm{O}_{3} \mathrm{NPs}$ in Escherichia coli cells by flow cytometry using light scattering method. El-ajaily et al., ${ }^{34}$ reported the antibacterial activity of $\mathrm{Cr}(\mathrm{VI})$ and $\mathrm{Cr}$ (III) complexes against $P$. aeruginosa bacteria. Ramesh et al synthesized nano-sized $\mathrm{Cr}_{2} \mathrm{O}_{3}$ by reduction of potassium dichromate solution with Arachis hypogaea leaf extract containing reducing sugars which act as reducing agent.

Ming Hua and co-workers ${ }^{35}$ have studied the nano-sized metal oxides, including ferric oxides, manganese oxides, aluminum oxides, titanium oxides, magnesium oxides and cerium oxides, which provide high surface area and specific affinity for heavy metal adsorption from aqueous systems. Tanya Tsoncheva et al., ${ }^{36}$ prepared mesoporous ceria and SBA-15 silica with iron and $\mathrm{Cr}_{2} \mathrm{O}_{3} \mathrm{NPs}$. The simultaneous presence of iron and chromium oxides lead to change in their dispersion, providing easier reducibility, higher catalytic activity and stability of the obtained materials in comparison with the corresponding mono-component ones. $\mathrm{P}$. Gibot and L. Vidal., ${ }^{37}$ prepared nanosized $\mathrm{Cr}_{2} \mathrm{O}_{3}$ by the common thermal decomposition of $\mathrm{Cr}\left(\mathrm{NO}_{3}\right)_{3} \cdot 9 \mathrm{H}_{2} \mathrm{O}$ chromium (III) nitrate nonahydrate. These pristine $\mathrm{Cr}_{2} \mathrm{O}_{3}$ NPs, with a slightly sintered sphere-shaped morphology, exhibited a $10 \mathrm{~nm}$ particle size with a monocrystalline character as demonstrated by the TEM and XRD correlation. Grzegorz Lota et al., ${ }^{38}$ reported single wall carbon nanotubes (SWNTs) filled and doped with $\mathrm{Cr}_{2} \mathrm{O}_{3}$ used as attractive electrodes for super capacitors. Selvam Sangeetha et al., ${ }^{39}$ reported a predominant solid state route, wherein a chromium-urea complex prepared under solvent free conditions was calcined at high temperature to obtain $\mathrm{Cr}_{2} \mathrm{O}_{3} \mathrm{NPs}$. The evolution with calcinations of $\mathrm{Cr}_{2} \mathrm{O}_{3} \mathrm{NPs}$ of catalytic interest, prepared from reduction of $\mathrm{K}_{2} \mathrm{Cr}_{2} \mathrm{O}_{7}$ with maleic acid, has been studied by S.M. El-Sheikh et al., ${ }^{40}$. Lifang Chen et al., ${ }^{41}$ demonstrated that the $\mathrm{Cr}_{2} \mathrm{O}_{3}$ spheres show an exceptional ability to remove azo"dye pollutant in water treatment. Thus, the porous $\mathrm{Cr}_{2} \mathrm{O}_{3}$ spheres with very good dye absorptions are expected to be useful in alternative absorption technologies. As $\mathrm{Cr}_{2} \mathrm{O}_{3} \mathrm{NPs}$ have wide applications in science and technology, an attempt has been made to synthesize $\mathrm{Cr}_{2} \mathrm{O}_{3}$ NPs by aqueous precipitation using ammonia as precipitating agent. This method involves a simple, cheap and one step process for the synthesis of $\mathrm{Cr}_{2} \mathrm{O}_{3}$ NPs. The obtained NPs of $\mathrm{Cr}_{2} \mathrm{O}_{3}$ have been characterized by XRD, TGA, IR, UV, SEM and TEM.

\section{METHODS AND MATERIALS}

\section{Chemicals}

All chemicals used in the experiment are analytic reagent grade. Chromium sulphate, $\mathrm{Cr}_{2}\left(\mathrm{SO}_{4}\right)_{3} \cdot 12 \mathrm{H}_{2} \mathrm{O}$ was purchased from Merck, India. Ammonium hydroxide (liquor ammonia) was purchased from SRL. Deionized water was used throughout the experiment.

\section{Synthesis of Chromium oxide}

$500 \mathrm{ml}$ of $0.1 \mathrm{M}$ solution of $\mathrm{Cr}_{2}\left(\mathrm{SO}_{4}\right)_{3}$ was taken and aqueous ammonia was added drop wise with constant stirring until the $\mathrm{pH}$ of the solution reached to 10 . The precipitates thus obtained were filtered by Buckner funnel and was washed several times with distilled water. The precipitates were dried in oven at $70^{\circ} \mathrm{C}$ for $24 \mathrm{hrs}$ and were calcined at $600^{\circ} \mathrm{C}$ in a muffle furnace for $5 \mathrm{hrs}$. Obtained material was ground and sieved through 100 mesh size sieve.

\section{Characterization techniques}

The microstructure of the particles was characterized by X-ray diffraction, Philips PW 11/ 90 diffractometer using nickel filtered CuK $\alpha$ ( $I=$ $1.5405 \AA$ ) radiations. The average diameter (D) of the $\mathrm{Cr}_{2} \mathrm{O}_{3}$ NPs has been calculated from the broadening of the XRD peak intensity after $\mathrm{K} \alpha_{2}$ corrections using the Debye-scherrer equation. Transmission electron microscopy measurements of the sample were taken on Hitachi $\mathrm{H} 7500$ with a $70 \mathrm{kV}$ accelerating voltage. The dispersions of NPs in water were placed on carbon-coated 400 mesh copper grids, allowed to dry at room temperature before taking measurement. The obtained 
micrographs were then examined for particle size and shape. TGA study was carried out using Perkin Elmer Pyris Diamond. The UV-visible spectra of asprepared aqueous solutions were taken by UV spectrophotometer (Perkin Elmer Lambda 25) in the wavelength range of $200-900 \mathrm{~nm}$ to determine the absorbance due to surface plasmon resonance (SPR) in the case of $\mathrm{Cr}_{2} \mathrm{O}_{3} \mathrm{NPs}$. The infrared spectra of adsorbents, adsorbates and adsorption adducts were recorded in $\mathrm{KBr}$ discs on a Perkin Elmer FTIR spectrophotometer (Model Perkin Elmer-1600 Series).

\section{RESULTS AND DISCUSSION}

\section{X-ray and IR studies}

$X$-ray diffraction of synthesized oxide is shown in Fig.1. The X-ray diffraction plot, shows peaks only due to $\mathrm{Cr}_{2} \mathrm{O}_{3}$ and no peak is detected due to any other material or phase indicating a high degree of purity of the as-synthesized sample. The broadening of the $\mathrm{X}$-ray diffraction lines, as seen in the Fig. 1 reflects the nano-particle nature of the sample. In X-ray diffraction, some prominent peaks were considered and corresponding d-values were compared with the standard. X-ray diffraction shows that the formed nano metal oxide is pure $\mathrm{Cr}_{2} \mathrm{O}_{3}$ and having hexagonal structure.

Sharpness of the peaks shows good crystal growth of the oxide nanoparticles. Average particle size ( $t$ ) of the particles have been calculated using from high intensity peak using the DebyeScherrer equation

$$
\mathrm{t}=\mathrm{K} \lambda / \mathrm{B} \cos \theta
$$

Where ' $\mathrm{t}$ ' is the average crystalline size of the phase under investigation, ' $\mathrm{K}$ ' is the Scherrer constant (0.89), ' $\lambda$ ' is the wave length of $X$ - ray beam used, ' $B$ ' is the fullwidth half maximum (FWHM) of diffraction (in radians) and ' $\theta$ ' is the Bragg's angle. The average crystalline size calculated is $45 \mathrm{~nm}$ which is in close agreement with the TEM results.

IR spectra of synthesized $\mathrm{Cr}_{2} \mathrm{O}_{3} \mathrm{NPs}$ show peak due to $\mathrm{M}-\mathrm{O}(\mathrm{Cr}-\mathrm{O})$ stretching at $569.30 \mathrm{~cm}^{-1}$ and $632.61 \mathrm{~cm}^{-1}$. Peaks at $3436.08 \mathrm{~cm}^{-1}$ and 1631.32 $\mathrm{cm}^{-1}$ may be due to the presence of moisture and carbon dioxide present in atmosphere [Fig. 2].

TGA and Surface Plasmon Resonance (SPR)

TGA transition shows no considerable weight loss upto $1000^{\circ} \mathrm{C}$ [Fig. 3]. It simply indicates that when $\mathrm{Cr}_{2}(\mathrm{OH})_{3}$ is heated, it converts into $\mathrm{Cr}_{2} \mathrm{O}_{3}$ and it is thermally stable in nature and we can use these synthesized NPs upto $1000^{\circ} \mathrm{C}$. Nanosized $\mathrm{Cr}_{2} \mathrm{O}_{3}$ particles show absorbance in the UV-visible region due to SPR, which originates due to the resonance of collective conduction electrons with incident electromagnetic radiations. It provides a sharp absorbance in the visible region around 460 $\mathrm{nm}$ [Fig. 4]. The shape of the resonance peak can be qualitatively related to the nature of NP. Small and uniform-sized NP with a narrow size distribution gives a sharp absorbance, whereas NP with a wide size distribution or any kind of aggregation shows a broad absorbance ${ }^{42-49}$.

\section{SEM and TEM studies}

SEM study was carried out to find out the surface morphology of synthesized $\mathrm{Cr}_{2} \mathrm{O}_{3}$. SEM

Table 1: X- Ray Diffraction Data for Chromium Oxide $\left(\mathrm{Cr}_{2} \mathrm{O}_{3}\right)$

\begin{tabular}{lcccc}
\hline $\begin{array}{l}\text { S. } \\
\text { No. }\end{array}$ & $\begin{array}{c}\mathbf{d}=\mathbf{I} \mathbf{2} \text { Sin } \\
\text { (Observed) }\end{array}$ & $\begin{array}{c}\mathbf{d}=\mathbf{I} \mathbf{2} \mathbf{S i n} \\
\text { (Reported) }\end{array}$ & $\begin{array}{c}\mathbf{I} / \mathbf{I} \times \mathbf{1 0 0} \% \\
\text { (Observed) }\end{array}$ & $\begin{array}{c}\mathbf{I} / \mathbf{1 0} \times \mathbf{1 0 0} \% \\
\text { (Reported) }\end{array}$ \\
\hline 1. & 3.62189 & 3.6210 & 63.22 & 62.90 \\
2. & 2.65863 & 2.6625 & 80.55 & 80.50 \\
3. & 2.47438 & 2.4760 & 100.00 & 100.00 \\
4. & 2.17017 & 2.1035 & 36.34 & 33.05 \\
5. & 1.81171 & 1.8045 & 27.53 & 27.50 \\
6. & 1.46172 & 1.4585 & 17.36 & 17.25 \\
7. & 1.42926 & 1.4300 & 31.84 & 30.99 \\
8. & 1.29440 & 1.2830 & 9.80 & 9.70 \\
9. & 1.08658 & 1.0565 & 9.18 & 9.00 \\
\hline
\end{tabular}




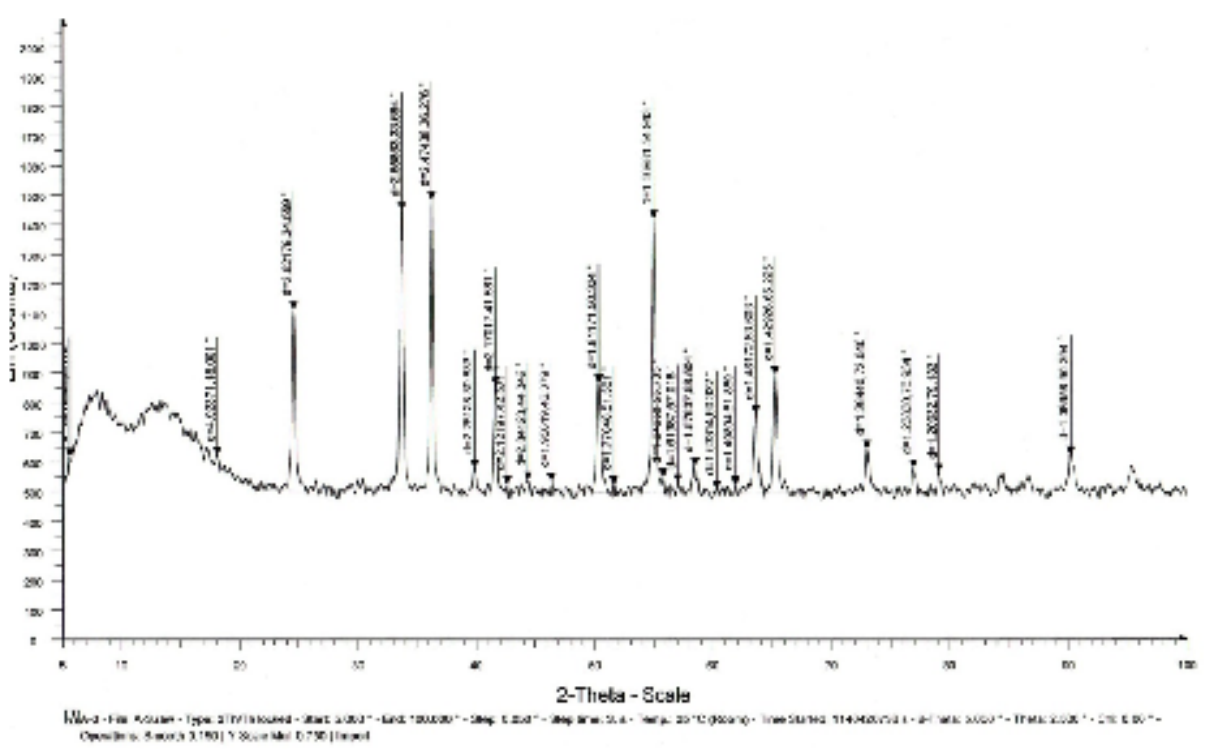

Fig. 1: X-ray diffraction for chromium oxide $\left(\mathrm{Cr}_{2} \mathrm{O}_{3}\right)$

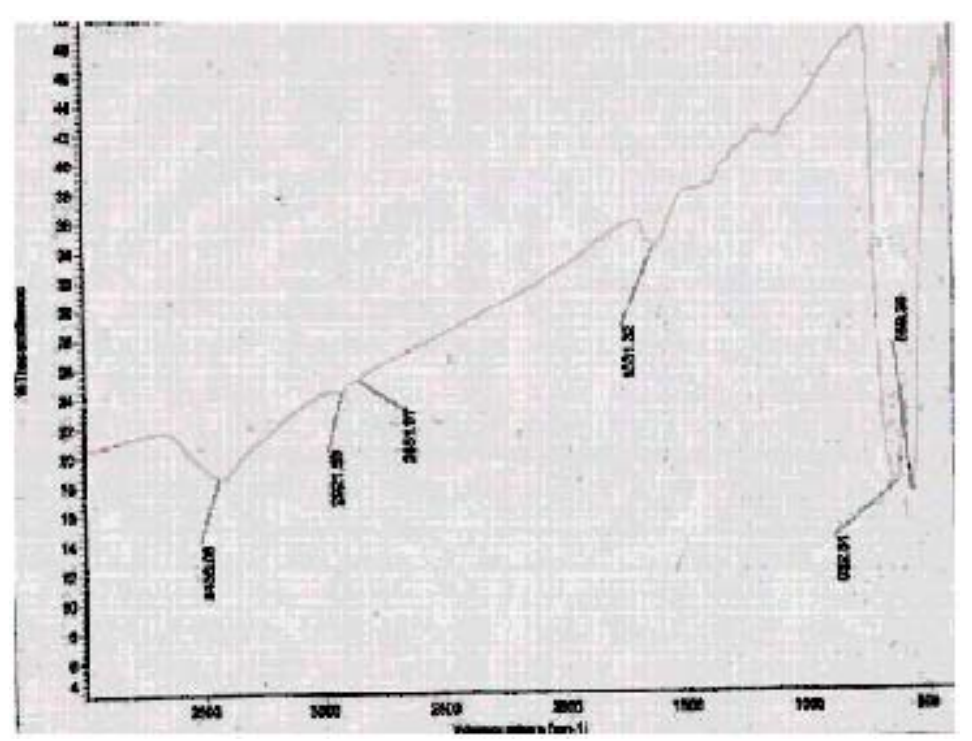

Fig. 2: IR Spectra of the synthesized chromium oxide nanoparticles

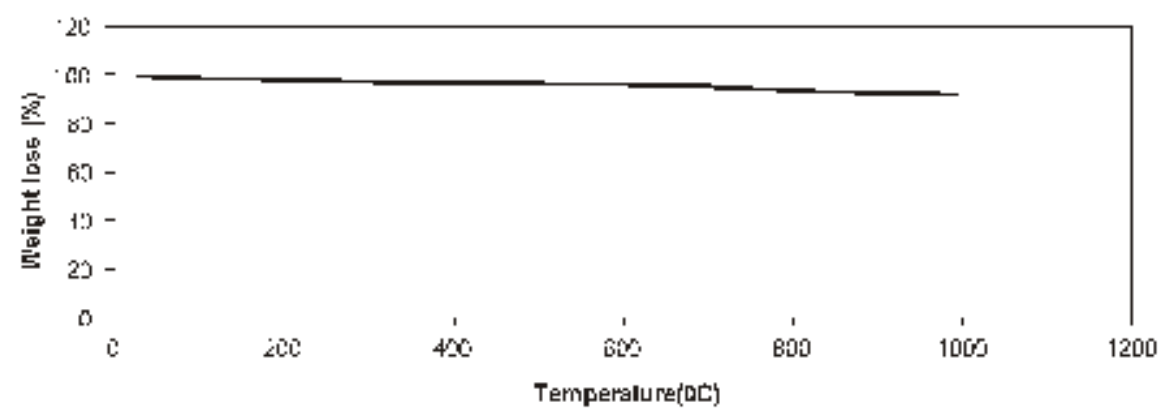

Fig. 3: TGA Graph of chromium oxide NPs 


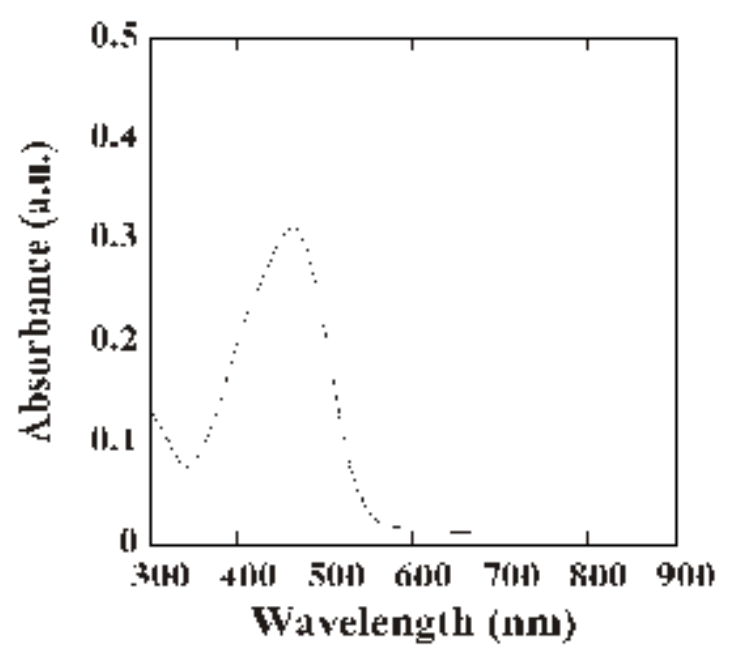

Fig. 4: UV-Visible Spectra of the chromium oxide

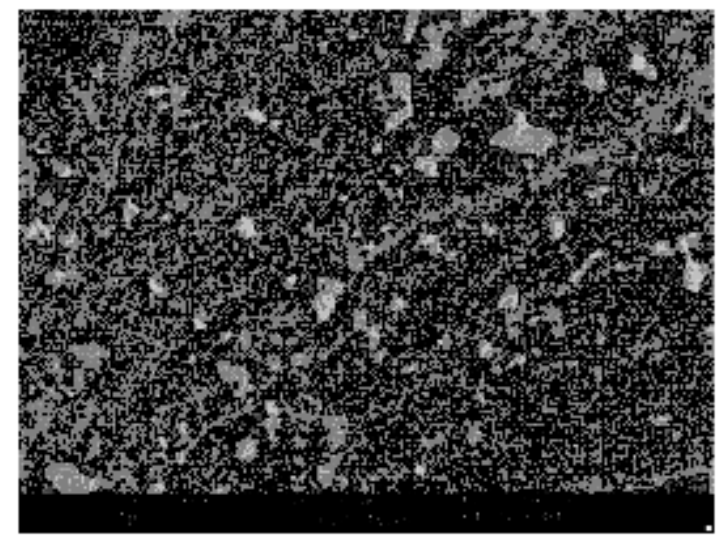

Fig. 5: SEM Image of chromium oxide $\left(\mathrm{Cr}_{2} \mathrm{O}_{3}\right)$

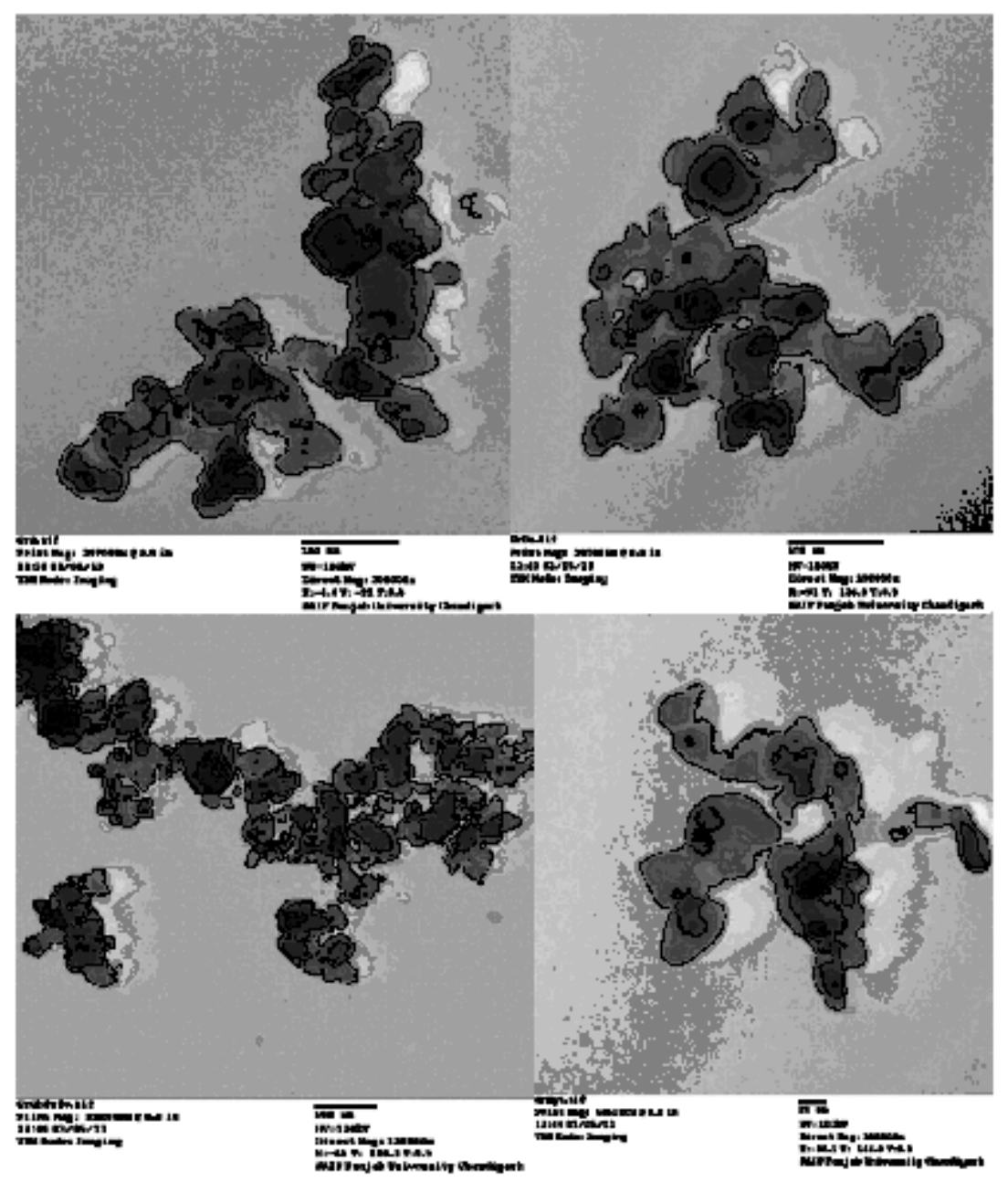

Fig. 6: TEM Images of chromium oxide $\left(\mathrm{Cr}_{2} \mathrm{O}_{3}\right)$ 

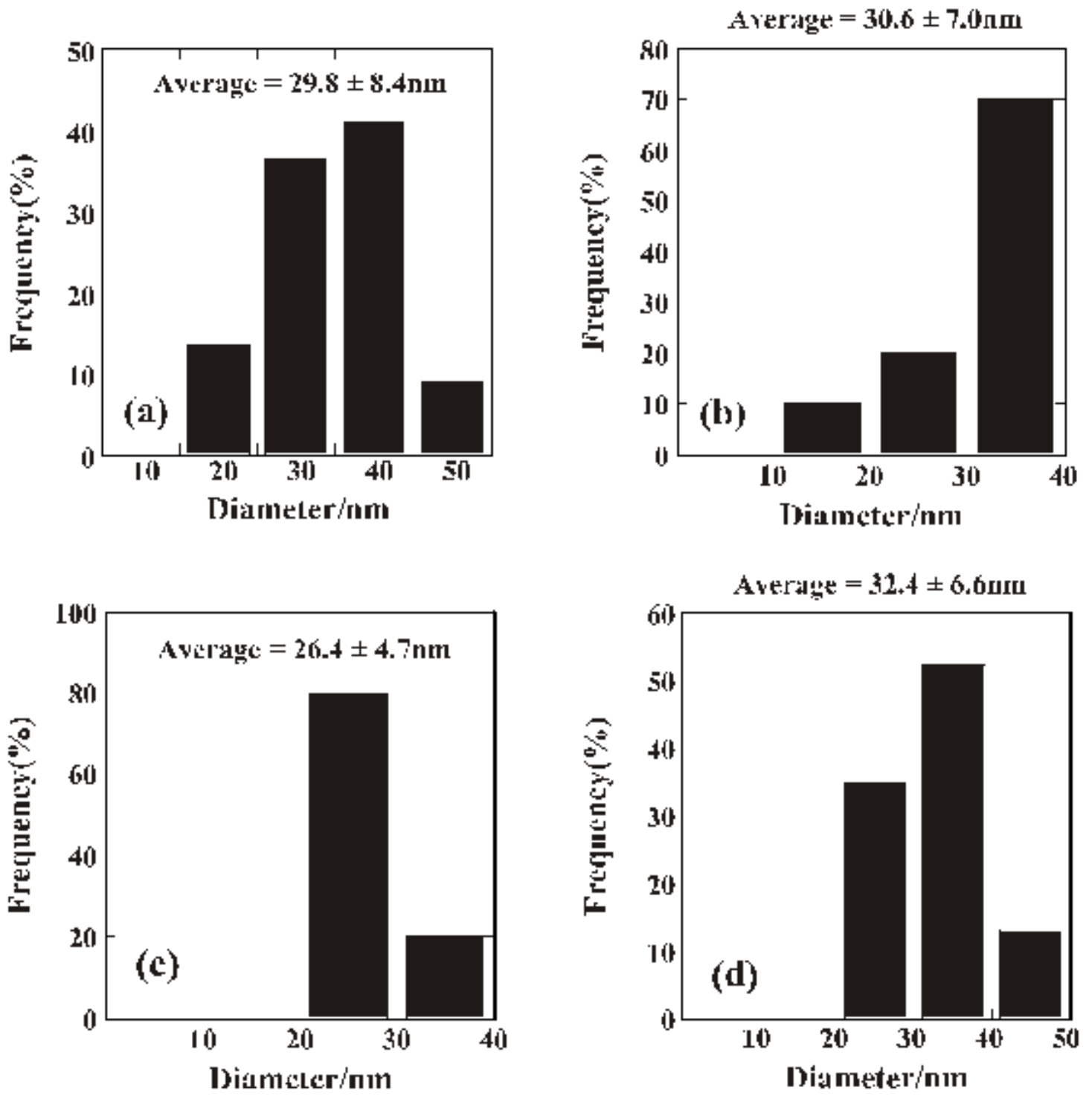

Fig. 7: Size Histograms of Figure 6

micrograph of the $\mathrm{Cr}_{2} \mathrm{O}_{3} \mathrm{NPs}$ have been represented in Fig. 5. SEM study shows that the chromium oxide is in pure form and the particles are beautiful white colored nanoparticles. TEM study was carried out to find out exact particle size of synthesized $\mathrm{Cr}_{2} \mathrm{O}_{3}$ NPs. Fig. 6 shows the TEM images of the synthesized $\mathrm{Cr}_{2} \mathrm{O}_{3}$ NPs. TEM images show that $\mathrm{Cr}_{2} \mathrm{O}_{3} \mathrm{NPs}$ are having particle size in the range of $20 \mathrm{~nm}-70 \mathrm{~nm}$ [Fig. 6]. The size distribution histograms for NPs provided their respective sizes as $32.9 \pm 13.3 \mathrm{~nm}$ [Fig. 7a], $32.2 \pm 9.3 \mathrm{~nm}$ [Fig. 7b], $31.4 \pm 9.5 \mathrm{~nm}$ [Fig. 7c], $28.8 \pm 8.9 \mathrm{~nm}$ [Fig. 7d], respectively.

\section{CONCLUSION}

Chromium oxide nanoparticles with hexagonal structure are synthesized successfully by aqueous precipitation method using ammonia as precipitating agent. From TEM study, it is found that particles are with average size of $20-70 \mathrm{~nm}$. XRD studies show that chromium oxide was formed as $\mathrm{Cr}_{2} \mathrm{O}_{3}$ instead of the commonly formed $\mathrm{CrO}_{2}$. The 
chemical reduction approach addressed in the present work on the synthesis of $\mathrm{Cr}_{2} \mathrm{O}_{3}$ nanoparticles are simple, cost effective, eco-friendly. The resultant nanoparticles are highly stable and reproducible that exhibit the greatest feasibility to further applications in the process of stropping knives, glasses, inks, paints and precursor to the magnetic pigment.

\section{REFERENCES}

1. Xu J. Z.; Zhu J. J.; Wang H.; Chen H. Y.; Analytical Letters, 2003, 36, 2723-2733.

2. LvW. Z.; Liu B.; Luo Z. K.; Ren X. Z.; Zhang P. X.; Journal of Alloys and Compounds, 2008, 465, 261-264

3. Zhou W.; Wachs I. E.; Kiely C. J.; Current Opinion in Solid State and Materials Science, 2012, 16, 10-22.

4. Altincekic T. G.; Boz I.; Aktürk S.; Journal of Nanoscience and Nanotechnology, 2008, 8, 874-877.

5. Zhou J.; Song H.; Chen X.; Zhi L.; Yang S.; Huo J.; Yang W.; Chemistry of Materials, 2009, 21, 2935-2940.

6. Yang M.; He J.; Hu X.; Yan C.; Cheng Z.; Zhao Y.; Zuo G.; Surface and Interface Physics papers in Physics, ASurface and interface

a. Physics papers A, 2011, 155, 692-698.

7. Segev-Bar M.; Haick H.; ACS Nano, 2013, 7, 8366-8378.

8. Kuban P.; Berg J. M.; Dasgupta P. K.; Analytical Chemistry, 2004, 76, 2561-256.

9. Sharma S. S.; Nomura K.; Ujihira Y.; Journal of Material Science, 1991, 26, 4104-4109.

10. Pillai V.; Kumar P.; Hou M. J.; Ayyub P.; Shah D.O.; Advance in colloid and Interface Science, 1995, 55, 241-269.

11. Rongcheng W.; Jiuhui Q.; Hong H.; Yunbo Y.; Journal of Beijing University of chemical technology (Natural science edition), 2003, 48, 2311-2316.

12. Zou W. R.; Han Z.; Zhang J. S.; Hangmin L.; Journal of Chemical and Engineering data, 2006, 51, 534-541.

13. Runping H.; Lina Z.; Xin Z.; Yanfang X.; Feng X.; Yinli L.; Wang Y.; Journal of Chemical Engineering, 2009, 149, 123-131.

14. Yang X.; Peng X.; Xu C.; Wang F.; Journal of Electrochemical Society, 2009, 156, C167C175.
15. Li C. L.; Zhao H. X.; Takahashi T.; Matsumura M.; Materials Science Engineering A, 2001, 308, 268-276.

16. Hwang J-Y; Seo D-S; Journal of Electrochemical Society, 2010, 157, J351J357.

17. Freemantle M.; Chemical and Engineering News Archive, 1998, 76, 8.

18. Jeffry I. F.; Ning L.; Daniel D.; Biochemistry, 1999, 38, 11593-11596.

19. Rotter H.; Landau M. V.; Carrera M.; Goldfarb D.; Herskowitz M.; Applied Catalysis $B, 2004,47,111-126$.

20. Rotter H.; Landau M. V.; Herskowitz M.; Environmental Science and Technology, 2005, 39, 6845-6850.

21. Chen L.; Song Z.; Wang X.; Prikhodko S. V.; Hu J.; Kodambaka S.; Richards R.; Applied Materials and Interfaces, 2009, 1, 19311937.

22. Bai Y-L; Xu H-B; Zhang Y.; Journal of Physics and Chemistry of Solids, 2006, 67, 25892595.

23. Santulli A. C.; Feygenson M.; Camino F. E.; Aronson M. C.; Wong S. S.; Chemistry of Materials, 2011, 23, 1000-1008.

24. Crzybowska B.; Sloczynski J.; Grabowski R.; Wcislo K.; Kozlowska A.; Stoch J.; Journal of Catalysis, 1998, 178, 687-700.

25. Wu P-W; Dunn B.; Journal of Sol-Gel Science and Technology, 2000, 19, 249-252.

26. Kim D-W; Shin S-I; Lee J-D; Oh S-G; Materials Letters, 2004, 58, 1894-1898.

27. El-Sheikh S. M.; Mohamed R. M.; Fouad O. A.; Journal of Alloys and Compounds, 2009, 482, 302-307.

28. Nakanishi K.; Tanaka N.; Accounts of Chemical Research, 2007, 40, 863-873.

29. Alrehaily L. M.; Joseph J. M.; Musa A. Y.; Guzonas D. A.; Wren J. C.; Physical 
Chemistry Chemical Physics, 2013, 15, 98107.

30. Ma Z.; Xiao Z.; van Bokhoven J. A.; Liang C.; Journal of Materials Chemistry, 2010, 20, 755-760.

31. Mougin J.; Bihan T. L.; Lucazeau G.; Journal of Physics and Chemistry of Solids, 2001, 62, 553-563.

32. Karunakaran C.; SakthiRaadha S.; Gomathisankar P.; Vinayagamoorthy P.; RSC Advances, 2013, 3, 16728-16738.

33. Khatoon I.; Vajpayee P.; Singh G.; Pandey A. K.; Dhawan A.; Gupta K. C.; Shanker R.; Journal of Biomedical Nanotechnology, 2011, 7, 168-169.

34. El-Ajaily M. M.; Abdlseed F. A.; Gweirif S. B.; E- Journal of Chemistry, 2007, 4, 461- 466.

35. Hua M.; Zhang S.; Pan B.; Zhang W.; Lv L.; Zhang Q.; Journal of Hazardous Materials, 2012, 211, 317-331.

36. Tsoncheva T.; Roggenbuck J.; Paneva D.; Dimitrov M.; Mitov I.; Fröba M.; Applied Surface Science, 2010, 257, 523-530.

37. Gibot P.; Vidal L.; Journal of the European Ceramic Society, 2010, 30, 911-915.

38. Lota G.; Frackowiak E.; Mittal J.; Monthioux M.; Chemical Physics Letters, 2007, 434, 73-
77.

39. Sangeetha S.; Basha R.; Sreeram K. J.; Sangilimuthu S. N.; Nair B. U.; Dyes and Pigments, 2012, 94, 548-552.

40. El-Sheikh S.M.; Mohamed R.M.; Fouad O. A.; Journal of Alloys and Compounds, 2009, 482, 302-307.

41. Chen L.; Song Z.; Wang X.; Prikhodko S. V.; Hu J.; Kodambaka S.; Richards R.; Applied Materials and Interfaces, 2009, 1, 19311937.

42. Liz-Marzan L. M.; Langmuir, 2006, 22, 32-41.

43. Schultz D. A.; Current Opinion in Biotechnology, 2003, 14, 13-22.

44. Sun Y.; Xia Y.; Analyst, 2003, 128, 686-691.

45. Schofield C. L.; Haines A. H.; Field R. A.; Russell D. A.; Langmuir, 2006, 22, 6707-6711.

46. El-Sayed M. A.; Accounts of Chemical Research, 2001, 34, 257-264.

47. Eustis S.; El-Sayed M. A.; Chemical Society Reviews, 2006, 35, 209-217.

48. Jaswal V. S.; Banipal P. K.; Kaura A.; Bakshi M. S.; Journal of Nanoscience and Nanotechnology, 2011, 11, 3824-3833.

49. Bakshi M. S.; Jaswal V. S.; Possmayer F.; Petersen N. O.; Journal of Nanoscience and Nanotechnology, 2010, 10, 1747-1756. 